\title{
Between Organization and Performance: When the Firm Meets Information and Communication Technologies
}

\author{
Mamadou SYLLA \\ Félix Houphouët-Boigny University, \\ Department of Economics and Management, Côte d'Ivoire
}

Received: May 15, 2019 Accepted: June 10, 2019 Online published: July 3, 2019 doi:10.5296/ijhrs.v9i3.14789

URL: https://doi.org/10.5296/ijhrs.v9i3.14789

\begin{abstract}
The implementation of One Capp software within the Middle Office has a very strong impact on the Re-Invoicing Servicing service; the importance of demonstrating the impact of ICT within an organization so that all banks are aware of it and can judge the impact of these tools within the various services. Hence, the contribution to a better understanding, by the employees, of the different techniques to obtain a better productivity within the firm concerned. Thus, the company is used as one of the many references in the field of new technologies.
\end{abstract}

Keywords: organization, performance, firm, meeting, ICT

\section{Introduction}

The world of the firm that emerged in the sixteenth century, is a world that continues to change. The latter plays a vital role in the economic development of humanity. The first activities, mostly considered exchanges, qualified the firm of merchant. Indeed, it was largely a matter of building boats, mines or weapons. The second, related to the bank, encountered a number of obstacles such as access to the loan. Indeed, at this time, the development of the firm is considered difficult.

The philosopher Plato considered that the work was largely for slaves. According to Aristotle, without exchange, it is impossible to create wealth. The concept of the firm of the time is therefore far from contemporary concepts of today. The firm "Modern" is born during the rebirth, when the economy changes radically. Indeed, mentalities are changing, from the emergence of capitalism in the Netherlands, through Amsterdam, the capital of "information \& knowledge", to the investment of England with the creation of the Compagnie des East 
Indies, the fourteenth century is marked by the openness of the West to the world.

In France, it is in 1803 that the company is born, when in 1694, this one sees it in England. The entrepreneurial mentality and the behavior of the entrepreneur are developing quite rapidly in the United States. The industrial revolution then comes into being, as the Enlightenment begins. Indeed, everything becomes a question of science and each problem is only a false problem when there is a scientific resolution for each one of them.

The industrial revolution stretching from 1780 to 1908 gave way to the appearance of technological innovations that unfolded in an accelerated manner towards the end of the 18th century. Modern firms accompanied by different legal forms appear. We then talk about the non-collective society, the limited partnership and finally the public limited company.

It was during the 1900s, that the industrial revolution will be propelled with the beginnings of Taylorism between 1908 and 1929. It will end during the Second World War during which the United States took the opportunity to develop the "American model" in the Western world. The globe is then impacted by this event and a duality is set up between fast growing countries such as Germany and the United States.

This era marks that of the modern firm with many changes such as the revolution of new technologies of information and communication. The concept of managerial firm attaching great importance to the speed of information is born. The terms ICT or NTIC are very often heard today because the use of these new information and communication technologies in the professional world has intensified in recent years.

Realizing the importance of the latter, NICTs integrate very quickly the world of the firm. While these new technologies are important factors in the evolution of jobs, jobs, and the relationships between human beings, they also change a number of elements such as the organization of work and the different styles of work. management or even the strategy of the firm and thus impacts directly or not the performance of the firm.

It is in the eighteenth century that the word company appears. At that time, it was a group of individuals with a common purpose. It is at the end of the 18th century that the meaning of the word company evolves. Indeed, the term adopts a more economic connotation and is often compared to a society. A business becomes an organization within which individuals have similar ideas (Dominique Bessire and Hervé Mesure, 2009).

The company defines itself "universally" as being a group of hierarchical human beings implementing intellectual, financial or physical means in order to better carry out its activities and thus make profit. The company creates a plethora of goods and services, but the wealth is also distributed.

There are several legal statuses as well as several sectors of activity. Companies will be classified according to their legal status. Indeed, they can come from the private or public sector. They will also be classified according to their sector of activity. There are three main sectors, since there is the primary sector, the secondary sector and finally the tertiary sector. The primary sector consists of activities related to natural resources, followed by the 
secondary sector regrouping all production activities and the tertiary sector covering all the service activities (Bouchard, G, et al., 1979). Finally, there are various functions within the company such as those related to accounting and financial, commercial, administrative, technical or security (Jean Claude Quéré, 2006).

\section{The Main Components of ICT}

\subsection{Technology}

Technology, is a science invented in Germany, and more precisely put in place by Reuleaux, great theoretician, mathematician, mechanic technician and also mechanic.

The latter is a science studying all the techniques as well as the technical life of being-humans from the beginning of humanity to today. As regards the general study of techniques, it must be universally recognized.

The technique represents "a group of movements, acts generally and mostly manual, organized and traditional contributing to achieve a goal known as physical or chemical or organic. (Marcel Mauss) Religion and art, the purpose of which is not material, as opposed to techniques, are therefore not considered to be techniques.

Technology is composed of a set of techniques and tools. This represents all instruments or devices defining the era of the machine. Therefore, it is a mode of organization and perpetuation (or transformation) of social relations, a manifestation of dominant thinking and behavioral patterns and an instrument of control and domination.

We can talk about technologies, such as navigation or agriculture. The techniques have the power to strongly impact the human being. We speak of the principle of paleoanthropology as well as the phenomenon of hominization. Technology has allowed man to have a conceptual thought, which makes him a creature of culture. In fact, from the conception of a material that has determined the relevant model of the tool, to the proposition of different types of social organization, and finally to the propulsion of new technologies, new and unprecedented human behaviors have occurred. beliefs and so a story. (Jean-Michel Besnier, 2011)

Technology impacts human being on the ability to manage and adjust to the natural environment. The technology will start with simple tools used by men with multiple means to travel and manage their environment.

Nowadays, the newest technologies, such as the telephone or the Internet, have made it possible for human beings to communicate easily and universally.

\subsection{Information}

"Information Science" called "Information Science" is a universal science thanks to the universal nature of information, itself, which is the object of science. This science, particularly studying information and the activities around it, aims to share the essential and profound elements that best meet the various needs of the information world.

The history of information science is closely related to mechanization, document processing, 
and more particularly to the search for documents.

After the second world war of 1945, a group of political, economic and other researchers thought it wise to know in order to better understand, to decide wisely and thus to act intelligently. They therefore consider information to be an essential element in order to carry out any action at best. The gathering of the information necessary for decision-makers is considered by them to be the main economic problem. (Friedrich A. Hayek, 1945)

The role of documentation is to provide information, however, if it increases considerably but is unclear, relevant and especially innovative for those who need it then it is characterized by inappropriate and therefore useless.

It is only between 1945-1955 that the mechanization of documentary research is the main objective of many works. Indeed, it is the renewal of the documentation. These years consist of the birth of new media and research processes offering inventors the opportunity to work on technical plethora and tools.

We talk about the link between these new processes in order to pave the way for the further development of the "thesaurus" and especially the combination or coordination of keywords.

Thanks to these various advances, the use of the computer has been propelled towards the analysis of documents as well as the search for information. (Hubert Fondin, 2005)

\section{The modification of information through multimedia}

Multimedia has changed the conditions of information. Indeed, it allows for a wider stakeholder panel. Indeed, a certain diversity is introduced. The implementation of this element dematerializes and decentralizes the information. Digitization provides instant information.

The world today is international, but the products currently on the market are considered as national, hence the importance of it. Multimedia through the Internet: Dematerialization makes it possible to obtain what we call "information paradises". (Henri Pigeat, 1996))

Today we are talking about an "information society". Indeed, society is far from the ideal information system we face. There is what is known as information overload and a problem with access to information.

This problem of access to information can be explained by two things: the difficulties related to information elements but also and particularly those related to the poverty of tools designed for users. The dissemination of information lacks structure. Nowadays information is overabundant, the corporate world is overloaded, although it is essential to generate information within a company. Knowing how to structure in order to carry out the analysis of information is just as essential.

The decompartmentalization of information makes the business world more efficient in terms of the way they view their business. Indeed, this allows the different services to reflect on the multiple activities present within the services. All of this makes it possible to set up a management style that strategically allocates important value to information. (Hakim Akrab, 
2012)

Informing one is an important element because it allows some prevention at the level of different potential risks. However, it must also consolidate its own strengths to be more appropriate and therefore improve performance. Until very long the communication was mainly oral. It's over the years, that many and various supports have emerged. This is an enrichment for the dissemination of information. (Marie-Nathalie Jauffret, 2014)

We are talking about the digital revolution as the third most important revolution of modern times. It is therefore important not to oppose this change but to follow these different permutations. Some thought that this evolution would make the man solitary and sedentary but unlike those that the majority could have thought, this evolution positively impacted the majority human being through communication between them but also through their ability to travel.

According to the author, the introduction of digital is a positively upsetting evolution of the traditional economy. Indeed, according to him, it is an opportunity for growth and employment. (Monika Siejka et al., 2013)

\subsection{Communication}

Communication is the action of communicating, transmitting, informing. Indeed, this one encompasses three important elements: the representation, the action on others or the expression.

Communication is at least between two people, the transmitter and the receiver. The content of communication is the message and the means defined as the channel is the intangible element through which the message flows. The sender is considered to be the source of the information, the receiver as the recipient.

The actors of the communication differ according to the type of communication.

The NICTs that stand for New Information and Communication Technologies are today ubiquitous at every level. Indeed, these transform the life of the individual. From the Internet, to television when it comes to printing, this digital arrival has revolutionized the world of communication.

New Information and Communication Technologies (ICTs), considered as all the products of economic activities contributing to the visualization, storage, processing and transmission of information by electronic means, are ubiquitous in today's world. the "modern" business world.

It was during the 1990s that ICTs developed considerably with the advent of the internet. Indeed, it was a tool that was used only in the military and then the scope has expanded since it became very useful in the scientific world.

ICTs therefore intervene in specific areas such as communication, IT or audiovisual. Indeed, this set of tools connected to each other contributes to a better responsiveness within a department or a company. (Pascal Petit, 2006) 


\section{The Influence of ICTs in Business}

\subsection{Information: From Technique to Science}

Information circulates since the invention of writing and printing. As a result, digital or audiovisual tools such as television, radio or the telephone, the use of which rapidly evolved during the 90s, developed. After the appearance of these various tools, the arrival of Wifi allowing wireless connection from phones or computers draw attention to another technological evolution.

Indeed, Generation $\mathrm{Y}$ knows a lot of changes related to the revolution of the New Technologies of Information and Communication. Moreover, these are constantly being modified.

All this leads to gaps in knowledge and requirements related to the approach of these new technologies. ICT, today also called NTIC are booming within the corporate world. However, although this can be seen positively, these are also limited.

We can consider several sectors that make up ICTs such as computer software, electronics or computer networks as well as "telecommunication" such as television, advertising, telephone or the Internet.

It is important to differentiate between the management of information and the management of information. Information management is defined as the set of activities for directing and verifying an organization related to the management of political, economic or other information.

The information makes it possible to put in place the relevant strategies in order to carry out a project. Indeed, the latter allows, taking into account the environment, to establish an adequate organization to be in adequacy and thus to better meet the various internal or external expectations. (Brigitte Guyot, 2012)

In a world in the process of technological change, documentary professionals must adapt to the various methods adopted.

Indeed, nowadays, the question of training in information science is omnipresent. It is essential to differentiate between the reality of technicians and that of information specialists. This change is leading to many changes in the approach to information science. This is why comprehensive training seems to be important in order to fully adapt to different methods. The documentary techniques, the different language courses, the multiple research methods or the main theories and principles in Information Science are, in my opinion, important elements to take into account during these different mutations.

So how to distinguish, enhance or further scientific information at a time when digital is omnipresent?

This is an important current issue that will be called open science. Indeed, it is not a myth or a distant legend but a very current problem. Indeed, the concept would be to reconcile several elements together such as the use of digital practices, the new valuations of these different 
practices and finally the different actions and new rights ensuring the ability to access and disseminate the various scientific results.

"The Technique is a set of knowledge and know-how specific to a trade or an art, and which makes it possible to act on things, to manufacture them, to shape them, to transform them. "(Hubert Fondin, 2003)

It is through two important elements that this passage from documentation to science takes place.

After the war: explosion of information: especially IST: Scientific and Technical Information (STI). The field of scientific research is changing through diversification into inter-discipline, new disciplines or sub-disciplines. This leads to a significant change in expectations and information needs of researchers. This made it clear that information was much more important than support. Indeed, the content has priority over the container.

It was in the 1960s that the term "documentation" was criticized and entered the path of disappearance.

For some researchers, the science of information is considered to be a more or less exact and autonomous science whose real object is the information on which many treatments are carried out via the computer, the new information technologies and communication or other techniques.

\subsection{The Science of Communication}

Communication and information are two different concepts. The different element and that of the relationship with the other. Indeed, the communication takes into account the other while the information only lingers very little if it is not at all on the relation to the other. This makes it possible to dissociate the information and the different receivers.

Communication is not the act of transmitting. Indeed, the fact of having a large amount of information does not ensure the good quality of the communication. The transmission of information is not the essential element. Indeed, what matters is the communication itself, and thus the fact of having a minimum of values in order to be able to exchange on various and multiple objects.

Communication cannot be defined in one word. Indeed, the latter encompasses several aspects. The arrival of ICT or the implementation of certain practices add to the many existing definitions of communication, one more.

The main roles of communication within the company are: to promote adaptation and cohesion to make working together more effective. Indeed, it is mainly thanks to good management, through good behavior management, but also to a good technique, through the various media, that communication within a company is effective. (Internal communication at the service of management, Philippe Détrie and Catherine Broyez)

The twentieth century marks the times of the communication revolution. However, the latter is divided into two dimensions, a political dimension and another rather cultural, in relation to 
equality, freedom or democracy. Indeed, information is more than important during these moments of crisis in which, communication is the representative set of the fight for freedom.

The second very different dimension is the considerable evolution of methods and new technologies facilitating the diffusion of communication and information. The twentieth century is the one in which it had on the one hand, the arrival of communication, on the other hand the various telecommunication tools such as radio, telephone or television. Indeed, the advent of one leads to the arrival and growth of the other.

We can distinguish here two dimensions: one cultural dimension and another considered technical. Although it is two different dimensions. One accompanies the other. Technical progress is very generally followed by protests.

The technical expression of the communication is in fact only utopian, because the techniques being supposed to create information, do not do it. The information carried by the techniques is therefore not communication.

\section{Enterprise ICT Management}

\subsection{ICT and Labor Management}

ICTs do not have a direct influence on the company's performance. Indeed, it is the different actions put in place following the integration of ICTs such as management or the different methods of dissemination that will have an impact on performance. The performance will therefore be born out of the organizational process brought about by ICT and thus justify a good return.

The link between ICT and performance is, however, mixed and opposite. Indeed, some think that computerization is directly linked to the performance of a company, while others suggest the opposite. Indeed, for many years, the operation of information systems was considered one of the major technical problems where the emerging difficulty was that of the computer tool.

The link between ICT and business performance stems from the link between these technologies and the workforce. Performance is therefore determined by the use of these new technologies. It is not the mere presence of ICTs that will improve performance but its use and adaptation within the company by its users. Here, the thesis is as follows: the interest that leaders bring to different technologies impacts management within SMEs and therefore the resulting performance. (Henri Isaac, 2006)

This article therefore argues that the performance of a company is not directly related to ICT but that it is rather the operating mode following the integration of ICT that will determine the performance of the latter. The link "ICT presence \& performance" is not automatically correct. However, there is a link between the frequency of use of information tools and the performance of SMEs. Just as there is a link between the number of people using the same tools within a company and the performance of it.

For many years now, companies have been very impacted by the various new information 
and communication technologies. Indeed, the multiple processes of organizations are very affected. This is mainly due to the evolution of these tools in business. New mobile technologies, such as Wi-Fi, are the ones that have changed a lot of things.

The frequent use of these different tools significantly affects the environment and the management of human relationships at work. Access to these new technologies makes it possible for different individuals to work at any time and in any place, hence telework, being remote work. Indeed, in order to integrate these tools within companies; the positive aspects of the latter are highly emphasized compared to the different limits and risks associated with their use.

The author defends the principle that they would allow a better reactivity, an important decisional autonomy, and finally an evolution related to the communication, the management or the organization. However, their limitations are equally present. Indeed, the author speaks of stopping major activities, a significant lack of reflection in decision-making, a too heavy information burden, an excessively important control of multiple activities or even the undifferentiation between work and non-work.

All of these aspects are very likely to have a significant impact on today's business and more particularly its performance. The author here argues that ICTs have an impact on business. It does not only speak of a negative impact; however, these aspects may be likely to outweigh the positive aspects and thus negatively impact the performance of the company. (Charles-Henri Besseyre of the horts \& Henri Isaac, 2006)

According to Romaun Chevallet and Frédéric Moatty, ICTs are more tools considered to improve productivity, management or even competition. In addition, these new technologies play an important role in data control. ICTs can simplify the different work processes. However, these can also negatively impact work methods. Indeed, the information burden can have a negative impact on the workload simply because it is too important.

Added to this is the omnipresence of different control methods or the dependence of individuals using these new technologies on computers. These many aspects can directly impact the performance of the company. It is therefore essential to establish a balance in order to maintain or improve working conditions and thus positively impact the performance of a company. (Eric Isaac, Eric Campoy \& Michel Kalika, 2007)

Today's business is constantly putting processes in place for better performance. In fact, these new technologies are integrated into the company in order to strengthen the communication and consolidate the management of the different interventions in order to better contribute to the decision making and thus to improve the performance. However, these do not only affect the operational part of a company, but also the different methods of communication or coordination impacting the management of the company or the environment.

As the previous author mentioned, while the positive aspects are more than ever present, so are ICT risks. The information overload, but also the responsiveness, the speed of the various processes or the time available for the execution of a given job have consequences on the salary in the feasibility of a task. These elements directly impact the performance of a 
company. (Eric Isaac, Eric Campoy \& Michel Kalika, 2007)

ICTs are introduced into the business world to improve the productivity of organizations. Indeed, these new technologies impact the organization in the sense that they modify the effectiveness of organizational devices. ICTs have an impact on coordination arrangements by increasing the possibilities of processing, assigning or assembling information essential to the organization within the organization. These impact different coordination mechanisms.

According to the author, there is a typology of ICTs realized on organizational aspects. He thus distinguishes computer tools, telecommunication tools, telematic tools.

Computer tools will allow the collection, processing and storage of data. Telematic tools will link information systems to each other. As for telecommunication tools, these are used for interindividual communication. These different devices have an impact on organizational devices. The author defines the organization as a set of mechanisms designed to solve the coordination problems encountered by the components of the organization.

According to Fidèle Nwamen, there are two notions of performance, one adopting a functional perspective or one whose perspective is processual. The first refers to activities such as finance, accounting or marketing. The second is closer to elements such as the management of innovation, communication or the supply chain.

The performance contributes to the justification of the link of the company and its daily organization. This makes it possible to say that whatever is undertaken in the company, every action within the various services that are part of the organization must positively impact the activity concerned. $97 \%$ of customers and $94.3 \%$ of suppliers would have enjoyed their use. Indeed, these different means of communication or information would help and encourage the speed of commercial transactions. This leads business leaders to approve the fact that the use of ICTs strengthens the links with the partners and thus positively impacts the commercial performance of the company (Fidèle Nwamen, 2006).

\subsection{ICT and Social Relations}

ICTs contribute from an economic point of view to improving the economic development of employment. In fact, thanks to simplified access to information, access to knowledge is accelerated, which contributes to a rapid change in the learning process. The integration of ICTs also increases profitability as well as income. Finally, it also contributes to the reduction of costs.

At the commercial level, this is a new production circuit thanks to the expansion of the e-commerce market. This contributes to the cost of supply, the development of innovations in service and response to consumer needs and finally enhances the brand image of the company.

According to Abdallah Alaoui, ICTs are first and foremost obligatory elements for the good management of a service or an organization. Indeed, according to him, the organizational competitiveness of a company is very strongly impacted by ICT. These last contribute very strongly to the improvement of this one. (Abdallah Alaoui, 2010) 
The integration of ICT is advantageous in the computer system. Indeed, the incorporation of ICT allows the relocation of production. The structure of the company is equally impacted. In addition, capturing information and creating new distribution channels improve labor productivity while expanding the market. Finally, it allows for a less hierarchical organization, thanks to simplified information sharing and better management of human resources.

ICTs contribute from a social point of view to better decision-making by different economic actors. They also contribute to educational and important work changes as they improve communication and contribute to better data processing.

In addition, elements such as flexibility, adaptation or the management of different stocks were important. Being able to work remotely, without having temporal or geographical constraints, can only be a positive point in terms of organization or adaptation to different contexts.

\section{The Undeniable Impact of the Latter Within Middle Office}

\subsection{An Environmental and Operational Challenge}

"Innovate", here is one of the words most often used by companies. Indeed, to innovate is to ensure a certain durability of the market. Innovating, in the world where competition is tough, is paramount. However, innovation, 21st century can' not work without taking into account the different environmental impacts that entails.

In fact, the sectors that have a significant impact on the environment largely involve the use of new information and communication technologies. ICT, therefore, have two needs today, that of satisfying these different sectors by providing them with quality products to improve their productivity, but must also face the challenge of respecting the environment. A new technology is defined as a tool for designing a modern solution emanating from a technological and scientific knowledge to meet a real need, to deploy it to make it a viable tool and finally to introduce this object on the market.

In general, ICTs improve the efficiency and effectiveness of different operations. The presence of ICT is important and allows through the use of these, that companies can be competitive. However, these new technologies whose use seems essential for a company with the desire to remain competitive in the market, have a very strong impact on the environment. Because of the positive impact within the companies, it seemed important to evaluate the significant impact of the latter on the environment.

The question of the match between innovation and the environment or even sustainable development, the ICT sector offers a very interesting research framework for several reasons. Indeed, the ICT sector is at the center of the many environmental challenges.

ICTs are part of an environmental service process called "Environmental Sustainability". This sector can potentially grant innovation and sustainable development in the sense that it is a sector in which technological innovation is omnipresent. 


\subsection{An Organizational and Human Challenge}

ICTs have profoundly changed working methods and organizational processes, particularly due to the use of certain social networks or the internet. This can be explained by the simple use of wireless communication tools such as telephones or computers. In effect, this has a strong impact on the relationship with others both within and outside the workplace (Chen and Nath 2005, Davis, 2002). This has allowed individuals to work at any time, without having to go to the workplace (Leclercs and Issac 2005, Lyytinen and Yoo 2002).

On a human level, the advent of ICT contributes to several advantageous elements such as the improvement of the possibilities of communication, management also of collaboration. Moreover, it allows a better reactivity as well as a greater autonomy in the decision-making. However, several disadvantages come to hinder these positive aspects such as the undeniable lack of boundary between work and non-work, the permanent continuity of work, the urgent aspect, the permanent and reinforced verification of activities, the lack of reflection in the various actions or the overload of information (Issac et al, 2006).

The new technologies contribute to some new flexibility within the company and have several promises for the company. In fact, the individual can have access to the professional information system at any time and in any place. The evolution of the individual production is one of the major positive elements of the implementation of ICT in business and this thanks to the decrease of the requirements related to the time and the space.

Added to this are many other positive aspects such as the evolution of flexibility, cost reduction, the clear improvement of communication as well as the exchange of knowledge. Indeed, these new technologies make it easy and immediate access to information, increased performance especially in decision-making and finally the positive evolution of responsiveness to customers. Some will even say that these new tools contribute to the best exercise of their activity through the dissemination of their know-how to internal as well as external clients.

Although the corporate phone is considered to be a tool contributing to the independence and mobility of employees, it contributes to the maintenance of "different hierarchical chains" within the company but also from the outside. The fact that the employee has the ability to use the mobile phone at any time, makes it traceable "digitally", which can be a permanent stress to them by the control and the continual monitoring of its activities. Moreover, this can hinder the individual's private life and thus no longer differentiate the latter from professional life.

In addition, the problems of interruption at work, due mainly to the use of this new technology promoting distraction instead of encouraging reflection. In addition, employees may feel oppression due to speed and immediacy, forcing them to make decisions urgently or at inappropriate times. These pejorative bridges are large enough to potentially negatively impact business productivity and thus be counterproductive.

Finally, it can also contribute to a lack of proximity between employees within the company, which can negatively impact productivity in the long term. Even further, the implementation 
of ICTs can lead to the elimination of posts, with very serious human and economic consequences.

\section{Presentation and Analysis of the Results}

\subsection{Regarding the "One Capp" Dematerialization Tool}

"One Capp" is defined as a workflow tool for validation of dematerialized invoices to know where the invoice is at the right time. It is a tool added to the SAP accounting tool and "Tymetrix" is itself a dematerialization tool. Indeed, the tool makes it possible to follow and pay all the invoices of various service providers internal or external to the bank by centralizing them. It contributes to a grain of time because access to information is fast, efficient and simple. Added to this is the security regarding the loss of the document.

Prior to the implementation of this tool, each department had an accounting tool for posting invoices. With the integration of "one Capp", all invoices are grouped in the same place in the "One Capp" tool. In addition, and finally, it enables colleagues in the finance division to have a report of the various business budgets using a tool directly. This tool allows suppliers to send invoices directly to the service in question, scan them and then save them by cost center. For each cost center "Resolutions Officers" as well as "Validators" are designated. An alert is sent to the resolution officer when there is an invoice to validate. Once validated, the invoice returns to the "validator", having received the same alert, validates it. The invoice will then be processed by the accounting which will make the payment.

"Tymetrix" being a dematerialization software also contributes to the centralization and validation of legal and non-legal invoices and thus proceed to the payment. However, this software will not make payments but will not trigger, not being able to do so. Like, the tool "One Capp", using information of the invoice can be found easily in the tool and take note of its status.

The "One Capp" tool is not unanimous: A set of positive but also negative points emerged from the qualitative study carried out.

The main positive points emerging from the study are the following:

It is a transition tool to obtain a concrete view of the status of the invoice and thus make the payment process faster, the tool allows the reduction of costs and allows to work remotely. It saves time by reducing settlement time but also the ease of access to information and multiple invoices and thus allows better productivity. It contributes to the rapid management of information and thus propels productivity.

It is an innovative and indispensable working method in order to be competitive on the market. Finally, it allows better access and monitoring of information, simple, fast and effective. Indeed, all employees have access to data and better data security.

We conclude that digitization generally makes a company's productivity better. It allows better access to data and better data security.

The main negative points of the study are: 
Some individuals have difficulty adapting to the object integration too fast and therefore the use is even more complicated. This contributes to the loss of time and money. Indeed, setting up training takes time and has a cost. It should be noted that these new technologies contribute to the elimination of posts. These can cause some dependence. Indeed, if a problem appears, there is the need to call on a computer scientist who does not have a view on the internal functioning of the problem tool. There is therefore a certain dependence when the operation of the tool in case of problems which can garner a waste of time. Do not forget, the implementation of these different technologies greatly reduces human contact.

Some think that oral communication in meetings or other is the most effective solution and adapt to access information as quickly as possible. According to them, there are many gaps in the development of this software does not simplify access to information. Among them, some do not believe in the improvement of Middle Office productivity with the advent of the tool "One Capp".

In addition, after studying the various services, we can read that the disappointment is present in some because the rendering does not correspond to what was heard. Employees strongly question the couple "Tymétrix-One Capp", not finding it so powerful since the arrival of "One Capp". We can talk about overvaluation.

Regarding the implementation of the software, to date, the training of all staff has not yet been effective for all, so it does not necessarily facilitate access or exchange information to the fact of not not having followed on the different clients and by the lack of training. The absence or lack of training from the beginning can cause problems with the use of the software and thus impact the activity negatively through the decline in productivity.

After analysis of the different results concerning the digitization as well as the research carried out. We can conclude that the ideas are shared. Indeed, the integration of digital is by unanimity.

\subsection{Regarding Teleworking}

The integration of the remote working day was largely unanimous. Indeed, the major part of the people who passed the interview was for the integration of the working day and more than half are for a second day of work. Indeed, the question of fatigue at work arose. Implementing a second day helps to overcome this fatigue and thus improve individual productivity. When we talk about the environment, health is linked to it. Indeed, in order to be productive, rest is an essential element to take into account.

Teleworking can be very interesting from a production point of view because if employees stay at home, they will not lose as much time in public transport. However, this also goes against the productivity of the company in the sense or if we have a training at the precise moment and that the various tools put at our disposal do not allow us to obtain the information for an unknown reason, then we will be slowed down in obtaining information which contributes to the slowdown in productivity in the Middle Office. In my opinion, if it makes work easier and more efficient, it is highly appreciable. 
A second day of telework would allow employees to be more rested, not stressed by transport and so can return home as soon as possible. The tools could allow them to work at home as if they were in business. Their productivity could be improved.

On the other hand, for work-study trainees, trainees or beginners who often need advice, training or recommendations, teleworking can disrupt work and long-term impact negatively on their learning. I think this is valid for other positions. Indeed, when there are emergencies, being far can be an obstacle.

\section{Theoretical Implications}

The ICT sector is one of the most ubiquitous sectors in the world today. The fact that a company is able to take ownership of ICTs easily is an important element of potential performance. Indeed, the link is clearly justified between the use of ICT by companies and the evolution of it in terms of competition. However, we have many problems with adapting to these new technologies.

\subsection{Regarding Dematerialization}

In view of the results obtained, concerning the integration of the software within the middle office, the opinions are divided, however the majority was for the integration of the tool and believes in the tool and its possibilities of improvement of the performance middle office activity. However, several conditions must be taken into account.

Indeed, training should be put in place in order to be able to use the tool perfectly and thus be effective in the work. On the other hand, others were not for the integration of this tool, because of the fear of change and thus the difficulty of adaptation. Regarding satisfaction after the integration of the tool, the Middle Officers are mostly disappointed with this tool for the moment.

In addition, the digital world is not that of the majority of employees within the group. Indeed, for many it is completely abstract, so it is important to reassure them by demonstrating simplicity, speed, efficiency, and thus the reliability of the tool.

\subsection{Regarding Teleworking}

According to Thierry BRETON (1994), teleworking is defined as a method of organizing distance work, usually performed by a natural person. He then speaks of two conditions, the first being that of distance work, which is different from where the person could potentially work if they were not teleworking. In addition, the person must be in a place where they will not be supervised and are not supposed to receive any order. The second condition is that of the use of new information and communication technologies, which the remote worker will necessarily be led to use.

Telework can affect the proximity of individuals. Moreover, when needed, distance is a major problem. In order to overcome this problem, it would be advisable to introduce only one telework day in order to match the demands of employees and the productivity of the company. 
However, the fact of being at home in a quiet environment, according to some, contributes to the well-being, almost total disappearance of stress and daily fatigue.

This technique also contributes to employee motivation by the absence of stress. This improves productivity and thus contributes to the performance of the various services.

The performance of a service or company can potentially drop if the implementation of new technologies is not carried out in such a way that all information related to the use of the latter is clear. In fact, as far as teleworking is concerned, if the various training courses have not been carried out with the different employees then the adaptation will be difficult like any other new technology.

Regarding work organization methods, it would be wise for the manager to reassure the employees about the adoption of the latter within the department. Indeed, not being comfortable with these new technologies, reassuring employees will provide some assurance and motivation for the use of these.

\section{Conclusion}

The entirety of the new information and communication technologies is not unanimous among firms. Although these new technological tools have the potential to contribute to the performance of the company through the organizational methods and the different changes that this entails, many challenges remain to be faced in order for productivity to reach its peak.

These new techniques put in place in order to access information more easily, quickly and simply is not always what actually happens. Indeed, if the support around the implementation of these new technologies is absent, then the rendering will not be the one expected. The impact of new technologies within the company can potentially be positive not only by the integration of new technologies but by the establishment of processes, working methods, training, and support to maximize its chances of being able to wait for the expected level of performance.

Among the many existing technological tools, we have been able to study those of digitalization through the integration of the "One Capp" dematerialization software as well as those referring to telecommunication means such as the mobile phone, the e-mail address as well as the telecommuting day. Indeed, we can notice that in a world where digital is one of the fundamental elements within a company in order to be able to compete on the market, to integrate a technological tool within a service or a company whose population does not come from Generation $\mathrm{X}$ or $\mathrm{Y}$ is quite complicated especially due to the problems of adaptation. The process of accompaniment is therefore essential so that the latter does not feel abandoned.

Today, judging the impact of new communication and information technologies within a company is not based on the mere integration of these technologies into the service but also and especially These have been integrated within the firm itself.

In the world of the modern firm in which we live, the absence of new technologies could be a 
handicap in the face of the present and increased competition on the market.

However, having these multiple tools does not mean being a leader or even having the assurance of being efficient.

Having these new technologies gives you the ability to be productive. Indeed, these devices being in constant evolution, are of great importance for the companies. Without them, some missions would have been more difficult to achieve. However, it is only if the elements such as the respect of the internal and external environment to the company, is taken into account.

Added to this is the fact of being balanced and not dependent on technology in place of human contacts in order to achieve sustainable development. In fact, in the opposite case, companies that see themselves using new technologies without equilibrium, thinking that this will improve productivity and thus performance, risk disappointing certain internal individuals external to the firm.

There are many challenges to face, however when we know the potential of these different techniques then the choice can be that of facing them in order to reconcile all of these elements. However, in a business world in which individuals come from such disparate generations that are so different from digitalization, are individuals ready to adapt? To trust the unknown? And finally, at what price?

\section{References}

Alaoui, A. (2010). Management of the Change, ICT and Organizational Competitiveness: The Case of the Company MBA-France. La Revue des Sciences de Gestion, 245-246(5), 81-89.

August von Hayek, F. (1945). The Use of Knowledge in Society. American Economic Review, XXXV, No.4, pp. 519-30. Retrieved 6/8/2019 from the World Wide Web: https://oll.libertyfund.org/titles/92

Besnier, J. (2011). Will New Technologies Reinvent Humanity?. Etudes, 414(6), 1-22. Laurence Burgorgue-Larsen.

Besseyre des Horts, C. H., \& Isaac, H. (2006). The impact of mobile ICTs on professional activities undertaken. HAL, Working Papers. 32. 10.3166/rfg.168-169.243-266.

Brousseau, E., \& Rallet, A. (1997). The Role of Information and Communication Technologies in Organizational Change. In B. Guilhon., P. Huard, M. Orillard, \& J.B. Zimmerman (eds.), Economie de la connaissance et Organisation; Entreprises, territoires, réseaux (pp. 1-17). Paris : L'Harmattan.

Fondin, H. (2002). The science of information and documentation or the relations between science and technology. Documentaliste-Sciences de l'Information, vol. 39(3), 122-129. doi:10.3917/docsi.393.0122.

Guyot, B. (2012). Information Management in Organizations: Elements of Methods. [Online] Available: https://archivesic.ccsd.cnrs.fr/sic_00665257/document (June 5, 2019).

Isaac, H., Campoy, E., \& Kalika, M. (2007). Information overload, urgency and ICT. The 


\section{Macrothink}

International Journal of Human Resource Studies

ISSN 2162-3058 2019, Vol. 9, No. 3

time effect of information technology. Management \& Avenir, 13(3), 149-168. doi:10.3917/mav.013.0149.

Jauffret, M. N. (2014). Knowing the alter to value information and impact the receiver. Dossier Gestion des risques

Joly, B. (2009). Presentation of the communication. In B. Joly, La communication (pp. 11-68). Louvain-la-Neuve, Belgique: De Boeck Supérieur.

Mauss, M. (2006). Techniques, Technology and Civilization. Nathan Schlanger

Nwamen, F. (2006). The Impact of Information and Communication Technologies on the Commercial performance of companies. La Revue des Sciences de Gestion, 218(2), 111-121.

Petit, P. (2006). ICT and the new economy: between mirages and miracles. Hermès, La Revue, 44(1), 39-45. https://www.cairn.info/revue-hermes-la-revue-2006-1-page-39.htm

Quéré, J. (2006). The Difficult Emergence of a New Management Function General Secretary of SMEs. Management \& Avenir, 8(2), 9-25.

Siejka, M., Heudin, J., Perriault, J., Ertzscheid, O., Vivant, M. \& Cardon, D. (2013). L'information, clés pour le futur. Documentaliste-Sciences de l'Information, 50(4), 26-37.

\section{Copyright Disclaimer}

Copyright for this article is retained by the author(s), with first publication rights granted to the journal.

This is an open-access article distributed under the terms and conditions of the Creative Commons Attribution license (http://creativecommons.org/licenses/by/4.0/). 